\title{
On-pump coronary artery bypass graft operation: Is one crossclamp application better than two?
}

\author{
Juan C. Araque, MD, ${ }^{a}$ Kevin L. Greason, MD, ${ }^{a}$ Zhuo Li, MS, ${ }^{b}$ Courtney N. Heins, BS, ${ }^{b}$ \\ John M. Stulak, MD, ${ }^{a}$ Richard C. Daly, MD, ${ }^{a}$ Lyle D. Joyce, MD, PhD, ${ }^{\text {a }}$ Rakesh M. Suri, MD, \\ Chaim Locker, MD, ${ }^{a}$ and Hartzell V. Schaff, MD
}

\begin{abstract}
Objectives: Several factors may increase the risk of stroke during coronary artery bypass grafting. These include age and atherosclerosis, which are not modifiable, and aortic manipulation, which may be modifiable. This study reports our experience with variable degrees of aortic manipulation (ie, single vs double [partial occlusion] aortic crossclamp techniques) and its influence on rate of operative stroke.
\end{abstract}

Methods: We performed a retrospective review of 8497 patients treated with isolated on-pump coronary artery bypass grafting from 1993 to 2010 . Demographics included an age of $66.8 \pm 10.3$ years and male sex in 6548 patients $(77.1 \%)$. Operative technique used the single aortic crossclamp in 2051 patients $(24.1 \%)$ and the partial aortic crossclamp in 6446 patients $(75.9 \%)$. To adjust for differences in baseline patient characteristics, 2 propensity-matched cohorts of 1333 patients each were created using Society of Thoracic Surgeons risk calculator variables.

Results: In the unmatched cohorts, stroke occurred in 25 patients $(1.2 \%)$ in the single aortic crossclamp cohort and in 98 patients $(1.5 \%)$ in the partial aortic crossclamp cohort $(P=.320)$. Logistic regression analysis demonstrated no significant relationship between stroke and aortic occlusion clamp technique (single clamp odds ratio, $0.80 ; 95 \%$ confidence interval, $0.51-1.24 ; P=.321$ ). In the matched cohorts, stroke occurred in 16 patients $(1.2 \%)$ in both the single and partial occlusion clamp cohorts $(P=1.00)$.

Conclusions: Given the methods and limitations of the data analysis, the single and partial aortic crossclamp techniques result in similar rates of stroke during on-pump coronary artery bypass grafting. ( $\mathrm{J}$ Thorac Cardiovasc Surg $2015 ; 150: 145-9)$

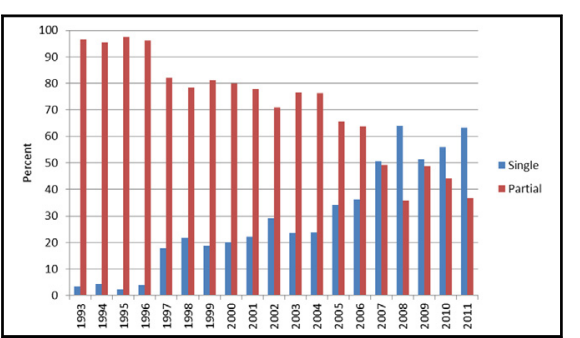

Aortic crossclamp technique, by year

Central Message

In this retrospective analysis of 8497 patients stroke rates were similar with single and partial occlusion aortic clamp techniques during onpump CABG.

Perspective

On-pump CABG is the mainstay technique for most surgeons for coronary artery revascularization. In this retrospective analysis of onpump CABG in 8497 patients, the stroke rate was a low $1.4 \%$ and was independent of year of operation; furthermore, the rate was similar with the single and partial occlusion aortic clamp techniques. Surgeons may take comfort with either of the methods.

See Editorial Commentary page 150
Controversy exists about the single aortic crossclamp (SC) and partial aortic crossclamp (PC) techniques and their respective rates of stroke during coronary artery bypass grafting (CABG). A meta-analysis from 2008 reported there was no benefit of the SC technique in comparison with the PC technique, ${ }^{1}$ whereas another study from 2011 suggested a significant reduction in the rate of stroke

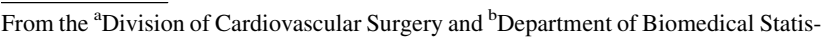
tics and Informatics, Mayo Clinic, Rochester, Minn.

Received for publication Nov 15, 2014; revisions received March 18, 2015; accepted for publication April 4, 2015; available ahead of print May 9, 2015.

Address for reprints: Kevin L. Greason, MD, Division of Cardiovascular Surgery, Mayo Clinic, Rochester, MN 55905 (E-mail: greason.kevin@mayo.edu). $0022-5223 / \$ 36.00$

Copyright (c) 2015 by The American Association for Thoracic Surgery http://dx.doi.org/10.1016/j.jtcvs.2015.04.010
}

associated with less aortic manipulation. ${ }^{2}$ Comparisons of the data are difficult because some of the studies contain small patient numbers, and others include off-pump CABG. The present study reports the stroke rates of a large number of patients treated with the SC or PC technique during isolated on-pump CABG.

\section{MATERIALS AND METHODS}

This study was approved by the institutional review board of Mayo Clinic. The operative reports were reviewed of 9797 patients who were treated with isolated CABG at the Mayo Clinic, Rochester, Minnesota, from 1993 to 2010. Each operation was reviewed and classified on the basis of the aortic crossclamp technique of an SC, PC (2-clamp technique), or all others.

Operative techniques were surgeon specific. This included the decision to use the SC or PC technique, the site for aortic cannulation, and the site for aortic crossclamp placement, the latter 2 of which were determined with 


\section{Abbreviations and Acronyms \\ $\mathrm{CABG}=$ coronary artery bypass grafting \\ $\mathrm{CI}=$ confidence interval \\ $\mathrm{OR}=$ odds ratio \\ $\mathrm{PC}=$ partial aortic crossclamp \\ $\mathrm{SC}=$ single aortic crossclamp \\ STS $=$ Society of Thoracic Surgeons}

direct examination of the aorta by the surgeon. No formal epiaortic ultrasound or transesophageal echocardiography program or process was used during the study period; specifically, data about the following Society of Thoracic Surgeons (STS) defined fields were not collected by the institution: AsmtAscAA, AsmtAoDx, and InOpTEE.

To create uniform study cohorts and to eliminate outliers of operative risk, we excluded patients undergoing operation off-pump, patients with a previous cardiac operation, patients undergoing operation while in cardiogenic shock, patients receiving inotrope medications, and patients in an emergency or salvage status. Patients whose operative report noted reapplication of the aortic crossclamp or PC also were excluded from the study. After the exclusions, the final study cohort totaled 8497 patients.

Two treatment cohorts were created that included those patients who received an SC $(\mathrm{n}=2051,24.1 \%)$ and those who received a PC (cohort, $\mathrm{n}=6446,75.9 \%$ ). Patients in the SC cohort all had distal and proximal bypass graft anastomoses performed during 1 crossclamp period. Patients in the PC cohort all had distal bypass graft anastomoses performed during 1 crossclamp period. The crossclamp was then removed, and the heart was reanimated. The PC was then applied to the aorta, and proximal bypass graft anastomoses were completed.

Baseline patient characteristics, operative data, and outcomes were collected on the basis of standard definitions set forth in the STS National Adult Cardiac Surgery database. The main outcome end points of the study were stroke and mortality defined as occurring within 30 days of operation or at any time during the index hospitalization. The diagnosis of stroke was made by the cardiac surgery team. No routine or standardized neurologic or radiologic evaluation of patients was conducted. Stroke was diagnosed as defined by the STS National Adult Cardiac Surgery database.

Descriptive statistics for categoric variables are reported as count (percentage), and continuous variables are reported as mean \pm standard deviation. Categoric variables were compared using chi-square or Fisher exact test, and continuous variables were compared using the 2-sample $t$ test or Wilcoxon rank-sum test, where appropriate. Logistic regression models were used for contingency analysis.

A propensity score was calculated. Patient characteristics included in the propensity score comprised all baseline patient characteristics used to calculate the STS predicted risk of mortality with 1 exception; data on the last creatinine level were not available for all patients. In place of the last creatinine level, a dichotomous variable of renal failure was used defined as the need for dialysis or a history of creatinine greater than $2.0 \mathrm{mg} / \mathrm{dL}$. Two treatment cohorts of 1333 patients each were selected with matched propensity scores within the SC and PC cohorts. All statistical tests were 2 sided.

\section{RESULTS}

The use of the PC has generally decreased every year since 1993 to present (Figure 1). During that time period, 17 surgeons performed a median of 274 operations (range, 1-1525); surgeon-specific use of the PC technique was a median of $77.4 \%$ (range, $0 \%-98 \%$ ). Baseline patient characteristics for the unmatched and matched cohorts are

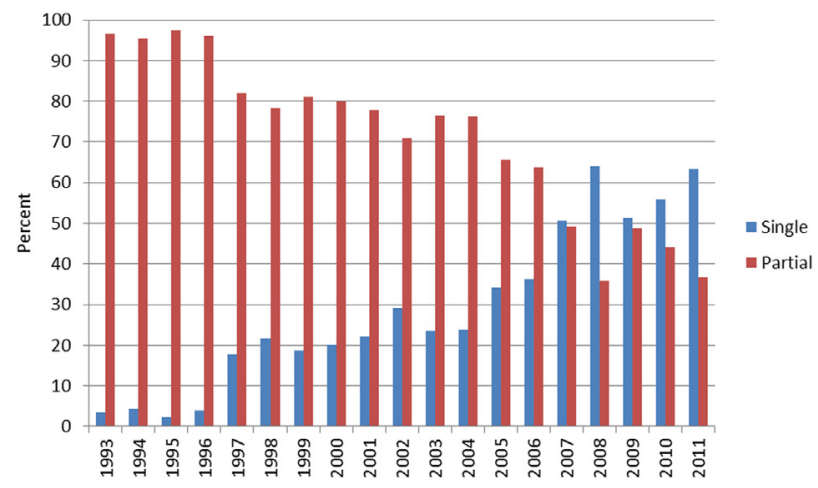

FIGURE 1. Aortic crossclamp technique, by year.

reported in Table 1. There were significant differences in baseline patient characteristics between the SC and PC cohorts in the unmatched cohorts, but not in the matched cohorts.

Operation data are reported in Table 2. Cardiopulmonary bypass time was less in the SC cohort ( $73.7 \pm 28.2$ minutes) in comparison with the PC cohort $(88.2 \pm 30$ minutes, $P<.001)$, and aortic crossclamp time was longer in the SC cohort $(54.5 \pm 20.9$ minutes $)$ than in the PC cohort $(50.7 \pm 17.5$ minutes, $P<.001)$. There were also differences between the 2 cohorts in the number of venous and arterial bypass grafts, and total number of bypass grafts; these differences persisted in the matched cohorts. However, the blood transfusion rate was similar in the unmatched SC cohort $(51.7 \%)$ and PC cohort $(52.0 \%$; $P=.811)$.

Stroke occurred in 25 patients $(1.2 \%)$ in the SC cohort and in 98 patients $(1.5 \%)$ in the PC cohort $(P=.320)$; mortality occurred in 22 patients $(1.1 \%)$ in the SC cohort and in 89 patients $(1.4 \%)$ in the PC cohort $(P=.285)$; and stroke or death occurred in 43 patients $(2.1 \%)$ in the SC cohort and in 170 patients $(2.6 \%)$ in the PC cohort $(P=.172)$. In the matched cohorts, stroke occurred in 16 patients $(1.2 \%)$ in both the SC and PC cohorts $(P=1.00)$; death occurred in 16 patients $(1.2 \%)$ in the SC cohort and in 13 patients $(1.0 \%)$ in the PC cohort $(P=.578)$; and stroke or death occurred in 30 patients $(2.5 \%)$ in the SC cohort and in 26 patients $(2.0 \%)$ in the PC cohort $(P=.587)$.

Univariate logistic regression models predicting operative stroke, mortality, or the combined end point of stroke or mortality are reported in Table 3. Multivariate predictors of stroke included age (odds ratio [OR], 1.07; $95 \%$ confidence interval $[\mathrm{CI}], 1.05-1.10 ; P<.001)$, presence of cerebrovascular disease (OR, 1.96; 95\% CI, 1.30-2.94; $P=.001)$, and presence of peripheral vascular disease (OR, 2.08; 95\% CI, 1.41-3.03; $P<.001$ ). Multivariate regression models predictive of death and the combined end point of stroke or death are further delineated 
TABLE 1. Baseline patient characteristics, by aortic clamp cohort

\begin{tabular}{|c|c|c|c|c|c|c|}
\hline \multirow[b]{2}{*}{ Variable } & \multicolumn{3}{|c|}{ Unmatched cohorts } & \multicolumn{3}{|c|}{ Matched cohorts } \\
\hline & $\begin{array}{l}\text { SC cohort } \\
(\mathrm{n}=\mathbf{2 0 5 1})\end{array}$ & $\begin{array}{l}\text { PC cohort } \\
(\mathrm{n}=6446)\end{array}$ & $P$ value & $\begin{array}{l}\text { SC cohort } \\
(n=1333)\end{array}$ & $\begin{array}{l}\text { PC cohort } \\
(n=1333)\end{array}$ & $P$ value \\
\hline Age (y) & $66.1(11.1)$ & $67.1(10.6)$ & $<.001$ & $66.2(10.8)$ & $66.3(10.8)$ & .766 \\
\hline BMI $\left(\mathrm{kg} / \mathrm{m}^{2}\right)$ & $30.0(5.7)$ & $29.4(5.1)$ & $<.001$ & $29.7(5.4)$ & $29.6(5.3)$ & .626 \\
\hline Ejection fraction & $0.55(0.13)$ & $0.56(0.14)$ & .147 & $0.56(0.13)$ & $0.56(0.13)$ & .617 \\
\hline STS predicted risk of mortality & $2.0(2.4)$ & $2.1(2.2)$ & .015 & $2.0(2.6)$ & $2.0(2.2)$ & .182 \\
\hline Male sex & $1561(76.1)$ & 4987 (77.4) & .238 & $998(74.9)$ & $990(74.3)$ & .727 \\
\hline Diabetes & $653(31.9)$ & 2035 (31.6) & .810 & $412(30.9)$ & $426(32.0)$ & .582 \\
\hline Dialysis & $21(1.0)$ & $58(0.9)$ & .61 & $10(0.8)$ & $10(0.8)$ & 1.000 \\
\hline Renal failure & $63(4.2)$ & $262(4.3)$ & .818 & $57(4.3)$ & $59(4.4)$ & .851 \\
\hline Hypertension & $1629(79.4)$ & $4802(74.5)$ & $<.001$ & $1027(77.0)$ & $1034(77.6)$ & .748 \\
\hline Immunosuppression & $84(4.1)$ & $263(4.1)$ & .976 & $52(3.9)$ & $48(3.6)$ & .684 \\
\hline Chronic lung disease & $232(11.3)$ & $687(10.7)$ & .406 & $139(10.4)$ & $146(11.0)$ & .659 \\
\hline Peripheral vascular disease & $329(16.0)$ & $1307(20.3)$ & $<.001$ & $225(16.9)$ & $225(16.9)$ & 1.000 \\
\hline Cerebrovascular disease & $281(13.7)$ & $883(13.7)$ & 1.00 & $186(14.0)$ & $181(13.6)$ & .772 \\
\hline Previous myocardial infarction & $876(42.7)$ & $2779(43.2)$ & .714 & $557(41.8)$ & $536(40.2)$ & .404 \\
\hline NYHA class III or IV & $488(76.0)$ & $5261(92.0)$ & $<.001$ & $1068(80.1)$ & $1070(80.3)$ & .919 \\
\hline Atrial arrhythmia & $199(9.7)$ & $824(12.8)$ & $<.001$ & $132(9.9)$ & $127(9.5)$ & .733 \\
\hline No. of diseased vessels & & & $<.001$ & & & .667 \\
\hline 1 & $121(5.9)$ & $124(1.9)$ & & $69(5.2)$ & $65(4.9)$ & \\
\hline 2 & $442(21.6)$ & $1051(16.3)$ & & $305(22.9)$ & $324(24.3)$ & \\
\hline 3 & $1486(72.5)$ & $5268(81.7)$ & & 959 (71.9) & $944(70.8)$ & \\
\hline Left main coronary artery stenosis & $688(33.6)$ & $1981(30.8)$ & .019 & $436(32.7)$ & $431(32.3)$ & .834 \\
\hline Aortic valve stenosis & $92(4.8)$ & $235(3.7)$ & .043 & $49(3.7)$ & $50(3.8)$ & .917 \\
\hline Mitral valve stenosis & $11(0.6)$ & $44(0.7)$ & .503 & $6(0.5)$ & $4(0.3)$ & .530 \\
\hline Aortic valve regurgitation (grade 3 or 4 ) & $20(1.0)$ & $41(0.7)$ & $<.001$ & $9(0.7)$ & $9(0.7)$ & .353 \\
\hline Mitral valve regurgitation (grade 3 or 4 ) & $99(5.0)$ & $343(5.4)$ & $<.001$ & $62(4.7)$ & $52(3.9)$ & .738 \\
\hline Tricuspid valve regurgitation (grade 3 or 4 ) & $58(2.9)$ & $132(2.1)$ & $<.001$ & $33(2.5)$ & $29(2.2)$ & .308 \\
\hline Status (urgent) & $660(32.6)$ & $1234(19.1)$ & $<.001$ & $389(29.2)$ & $371(27.8)$ & .425 \\
\hline
\end{tabular}

SC, Single aortic crossclamp; PC, partial aortic crossclamp; BMI, body mass index; STS, Society of Thoracic Surgeons; NYHA, New York Heart Association.

in Table 4. The technique of aortic crossclamp was not predictive of stroke $(P=.321)$, death $(P=.286)$, or the combined end point of stroke or death $(P=.174)$.

\section{DISCUSSION}

In this retrospective analysis of 8497 patients, we studied 2 different aortic crossclamp techniques and their associated stroke rates during isolated on-pump CABG. An SC was performed in 2051 patients (241\%) and a PC was performed in 6446 patients $(75.9 \%)$. Operative stroke occurred in $1.2 \%$ of the patients in the SC cohort and
$1.5 \%$ of the PC cohort in the unmatched cohorts $(P=.320)$, and $1.2 \%$ in each of the matched cohorts $(P=1.00)$. Logistic regression analysis showed that the aortic crossclamp technique was not predictive of stroke, death, or the combined end point of stroke or death; furthermore, stroke rate was independent of year of operation.

Stroke is an unfortunate complication of CABG. In the present day, stroke occurs in up to approximately $2 \%$ of patients after operation. ${ }^{2,3}$ Once stroke occurs, it may portend a poor prognosis because stroke is a strong

TABLE 2. Operation data, by aortic clamp cohort

\begin{tabular}{|c|c|c|c|c|c|c|}
\hline \multirow[b]{2}{*}{ Variable } & \multicolumn{3}{|c|}{ Unmatched cohorts } & \multicolumn{3}{|c|}{ Matched cohorts } \\
\hline & $\begin{array}{l}\text { SC cohort } \\
(n=2051)\end{array}$ & $\begin{array}{l}\text { PC cohort } \\
(n=6446)\end{array}$ & $P$ value & $\begin{array}{l}\text { SC cohort } \\
(\mathrm{n}=1333)\end{array}$ & $\begin{array}{l}\text { PC cohort } \\
(n=1333)\end{array}$ & $P$ value \\
\hline Cardiopulmonary bypass time (min) & $73.7(28.2)$ & $88.2(30.0)$ & $<.001$ & $71.9(28.4)$ & $82.0(27.0)$ & $<.001$ \\
\hline Aortic crossclamp time (min) & $54.5(20.9)$ & $50.7(17.5)$ & $<.001$ & $53.3(21.4)$ & $48.9(16.3)$ & $<.001$ \\
\hline No. of distal bypass grafts & $2.9(0.9)$ & $3.3(0.8)$ & $<.001$ & $3.0(0.9)$ & $3.2(0.9)$ & $<.001$ \\
\hline No. of distal artery bypass grafts & $1.4(0.8)$ & $1.2(0.6)$ & $<.001$ & $1.5(0.9)$ & $1.3(0.7)$ & $<.001$ \\
\hline No. of distal vein bypass grafts & $1.5(1.1)$ & $2.1(0.9)$ & $<.001$ & $1.5(1.1)$ & $1.9(0.9)$ & $<.001$ \\
\hline
\end{tabular}

$S C$, Single aortic crossclamp; $P C$, partial aortic crossclamp. 
TABLE 3. Univariate predictors of outcome

\begin{tabular}{|c|c|c|c|c|}
\hline \multirow{2}{*}{ Variable } & \multirow{2}{*}{$\begin{array}{l}\text { Odds } \\
\text { ratio }\end{array}$} & \multicolumn{2}{|c|}{$95 \% \mathrm{CI}$} & \multirow{2}{*}{$\begin{array}{c}P \\
\text { value }\end{array}$} \\
\hline & & Lower & Upper & \\
\hline \multicolumn{5}{|l|}{ Stroke } \\
\hline Age & 1.08 & 1.06 & 1.09 & $<.001$ \\
\hline Cardiopulmonary bypass time & 1.01 & 1.00 & 1.01 & .003 \\
\hline Ejection fraction & 0.98 & 0.97 & 1.00 & .012 \\
\hline Male sex & 0.69 & 0.51 & 0.92 & .013 \\
\hline Immunosuppression & 2.13 & 1.10 & 4.00 & .025 \\
\hline Cerebrovascular disease & 2.78 & 1.89 & 4.17 & $<.001$ \\
\hline Peripheral vascular disease & 2.63 & 1.82 & 3.85 & $<.001$ \\
\hline Previous myocardial infarction & 1.54 & 1.08 & 2.22 & .018 \\
\hline NYHA class III or IV & 1.88 & 1.07 & 3.29 & .027 \\
\hline Arrhythmia & 2.00 & 1.28 & 3.03 & .002 \\
\hline $\begin{array}{l}\text { Mitral valve regurgitation } \\
\text { grade III or IV }\end{array}$ & 2.59 & 1.43 & 4.68 & .002 \\
\hline $\begin{array}{l}\text { Tricuspid valve regurgitation } \\
\text { grade III or IV }\end{array}$ & 2.99 & 1.66 & 5.39 & $<.001$ \\
\hline $\mathrm{SC}$ & 0.80 & 0.51 & 1.24 & .321 \\
\hline Operation y & 0.99 & 0.95 & 1.02 & .433 \\
\hline \multicolumn{5}{|l|}{ Mortality } \\
\hline Age & 1.07 & 1.05 & 1.09 & $<.001$ \\
\hline Ejection fraction & 0.97 & 0.95 & 0.98 & $<.001$ \\
\hline Cardiopulmonary bypass time & 1.02 & 1.01 & 1.02 & $<.001$ \\
\hline Male sex & 0.54 & 0.37 & 0.81 & .002 \\
\hline Renal failure & 0.38 & 0.20 & 0.72 & .003 \\
\hline Chronic lung disease & 2.84 & 1.84 & 4.38 & $<.001$ \\
\hline Immunosuppression & 3.23 & 1.79 & 5.88 & $<.001$ \\
\hline Cerebrovascular disease & 1.96 & 1.25 & 3.03 & .003 \\
\hline Peripheral vascular disease & 1.89 & 1.25 & 2.78 & .003 \\
\hline Previous myocardial infarction & 2.33 & 1.59 & 3.45 & $<.001$ \\
\hline NYHA class III or IV & 2.44 & 1.27 & 4.68 & .007 \\
\hline Aortic valve stenosis & 2.17 & 1.09 & 4.35 & .029 \\
\hline $\begin{array}{l}\text { Mitral valve regurgitation } \\
\text { grade III or IV }\end{array}$ & 3.47 & 1.99 & 6.06 & $<.001$ \\
\hline $\begin{array}{l}\text { Tricuspid valve regurgitation } \\
\text { grade III or IV }\end{array}$ & 3.86 & 1.90 & 7.86 & $<.001$ \\
\hline Status (urgent) & 1.54 & 1.03 & 2.31 & .038 \\
\hline $\mathrm{SC}$ & 0.77 & 0.48 & 1.24 & .286 \\
\hline Operation y & 0.93 & 0.89 & 0.97 & $<.001$ \\
\hline \multicolumn{5}{|l|}{ Stroke or mortality } \\
\hline Age & 1.08 & 1.06 & 1.09 & $<.001$ \\
\hline Ejection fraction & 0.98 & 0.97 & 0.99 & $<.001$ \\
\hline Cardiopulmonary bypass time & 1.01 & 1.01 & 1.02 & $<.001$ \\
\hline Diabetes & 1.27 & 0.91 & 1.76 & .162 \\
\hline Cerebrovascular disease & 2.51 & 1.75 & 3.62 & $<.001$ \\
\hline Male sex & 0.69 & 0.51 & 0.92 & .013 \\
\hline Chronic lung disease & 2.07 & 1.47 & 2.93 & $<.001$ \\
\hline Immunosuppression & 2.50 & 1.56 & 4.00 & $<.001$ \\
\hline Cerebrovascular disease & 2.38 & 1.72 & 3.23 & $<.001$ \\
\hline Peripheral vascular disease & 2.33 & 1.75 & 3.13 & $<.001$ \\
\hline Previous myocardial infarction & 1.85 & 1.41 & 2.44 & $<.001$ \\
\hline NYHA class III or IV & 1.91 & 1.24 & 2.93 & .003 \\
\hline Arrhythmia & 1.82 & 1.30 & 2.56 & $<.001$ \\
\hline Aortic valve stenosis & 1.89 & 1.11 & 3.23 & .019 \\
\hline $\begin{array}{l}\text { Mitral valve regurgitation } \\
\text { grade III or IV }\end{array}$ & 3.05 & 1.98 & 4.70 & $<.001$ \\
\hline
\end{tabular}

(Continued)
TABLE 3. Continued

\begin{tabular}{lcccc}
\hline & \multirow{2}{*}{$\begin{array}{c}\text { Odds } \\
\text { Variable }\end{array}$} & \multicolumn{2}{c}{$\mathbf{9 5 \%}$ CI } & $\boldsymbol{P}$ \\
\cline { 3 - 4 } & ratio & Lower & Upper & value \\
\hline $\begin{array}{l}\text { Tricuspid valve regurgitation } \\
\text { grade III or IV }\end{array}$ & 2.99 & 1.66 & 5.39 & $<.001$ \\
SC & & & & \\
Operation y & 0.79 & 0.56 & 1.11 & .174 \\
\hline
\end{tabular}

CI, Confidence interval; NYHA, New York Heart Association; $S C$, single aortic crossclamp.

independent predictor of death at 30 days and 1 year. ${ }^{4}$ Several factors may increase the risk of stroke during CABG. These include age and atherosclerosis, which are not really modifiable, and aortic manipulation, which to a certain extent is modifiable. ${ }^{5}$

There is controversy in the literature about stroke rates among the various techniques of clamp occlusion of the aorta during on-pump CABG. In a 2008 meta-analysis, Raja and colleagues ${ }^{1}$ reported no benefit of the SC technique over the multiple aortic crossclamp techniques in 490 patients enrolled in 6 randomized controlled studies. That article itself is contentious, however, because the authors did not perform a formal statistical analysis of the data in the reviewed studies. As for the 6 randomized controlled studies, the sample sizes were small and variable (ie, 24-134 patients).

It is intuitive that less aortic manipulation would result in less risk of stroke. This concept is supported with data from the appropriately named "anaortic" off-pump CABG technique, which is performed without aortic manipulation.

TABLE 4. Multivariate predictors of outcome

\begin{tabular}{|c|c|c|c|c|}
\hline \multirow[b]{2}{*}{ Variable } & \multirow[b]{2}{*}{ Odds ratio } & \multicolumn{2}{|c|}{$\mathbf{9 5} \% \mathrm{CI}$} & \multirow[b]{2}{*}{$P$ value } \\
\hline & & Lower & Upper & \\
\hline \multicolumn{5}{|l|}{ Stroke } \\
\hline Age & 1.07 & 1.05 & 1.10 & $<.001$ \\
\hline Cerebrovascular disease & 1.96 & 1.30 & 2.94 & .001 \\
\hline Peripheral vascular disease & 2.08 & 1.41 & 3.03 & $<.001$ \\
\hline \multicolumn{5}{|l|}{ Mortality } \\
\hline Age & 1.06 & 1.04 & 1.09 & $<.001$ \\
\hline Ejection fraction & 0.97 & 0.96 & 0.99 & $<.001$ \\
\hline Cardiopulmonary bypass time & 1.02 & 1.01 & 1.02 & $<.001$ \\
\hline Male sex & 0.56 & 0.37 & 0.86 & .008 \\
\hline Immunosuppression & 2.38 & 1.25 & 4.55 & .008 \\
\hline Status (urgent) & 1.81 & 1.13 & 2.90 & .014 \\
\hline \multicolumn{5}{|l|}{ Stroke or mortality } \\
\hline Age & 1.06 & 1.05 & 1.08 & $<.001$ \\
\hline Ejection fraction & 0.99 & 0.98 & 1.00 & .005 \\
\hline Cardiopulmonary bypass time & 1.01 & 1.01 & 1.02 & $<.001$ \\
\hline Immunosuppression & 2.17 & 1.30 & 3.57 & .003 \\
\hline Cerebrovascular disease & 1.56 & 1.12 & 2.22 & .009 \\
\hline Peripheral vascular disease & 1.79 & 1.32 & 2.44 & $<.001$ \\
\hline Previous myocardial infarction & 1.47 & 1.09 & 2.00 & .012 \\
\hline
\end{tabular}

$C I$, Confidence interval. 
In one such study, Vallely and colleagues ${ }^{6}$ reported an incredibly low associated stroke rate of only $0.08 \%$ with the technique; importantly though, it was not zero. ${ }^{6,7}$ It is conceivable that there is some inherent risk of stroke associated with any cardiac operation, and that risk may increase with manipulation of the ascending aorta with the aortic crossclamp. However, our data would suggest that the risk does not increase further with the additional aortic manipulation of the PC.

The present discussion is not designed to compare our outcomes with those of the "anaortic" off-pump technique. It is only to bring attention to the associated nonzero stroke rate with both techniques. There are many competing variables to be considered in an on-pump versus "anaortic" off-pump comparison: patient selection, operator experience, number of bypass grafts performed, graft patency, and patient survival, just to list a few. ${ }^{8}$ Of importance to our study is that on-pump CABG is the main technique with the majority of surgeons; for example, more than $80 \%$ of operations performed in the SYNTAX (synergy between percutaneous coronary intervention with taxus and cardiac surgery) study were performed with cardiopulmonary bypass. ${ }^{3}$ The "anaortic" off-pump technique may be a more specialized technique, representing less than $15 \%$ of operations in one large series.

\section{Study Limitations}

Two identified limitations in this study are the retrospective study design and statistical analysis of the data. Because this is an observational study, several biases are inherent to the study: (1) We were unable to determine the decision process in the choice of clamp technique; (2) some strokes may have been missed because no routine, standardized postoperative neurologic or radiologic assessment was performed; (3) no documented assessment of the ascending aorta was performed; and (4) important data (ie, creatinine and hemoglobin) were not recorded throughout the duration of the study. Because this is a retrospective study, however, these biases should have applied equally to both cohorts.

Due diligence has been done to mitigate bias given the large number of patients and the use of multivariate analysis; furthermore, propensity matching was done of paired baseline patient characteristic data, which demonstrated similar outcome. There were significant differences in baseline patient characteristics, however, and to make the propensity matching work it is possible that only patients with good risk in the PC group were selected. Although the paired groups had similar baseline STS patient characteristics, the groups are undoubtedly not the same. To address the issue of bias with a randomized study would require a large number of patients. To be specific, an $80 \%$ power calculation assuming a significance level of $5 \%$ would require 1610 patients to show a reduction in stroke rate from $1.6 \%$ to $0.8 \%$. The completion of such a study in today's practice environment would be costly and challenging.

\section{CONCLUSIONS}

On-pump CABG is associated with a low risk of stroke. On the basis of this large series of patients, the stroke rate with the SC technique appears similar in comparison with that of the PC technique. Strengths of this study include the large number of patients operated over a 20 -year period, and the concordant conclusion arrived at with both multivariate and propensity matching analysis. The findings should be framed in the context of the limitations of the statistical methods used. Further study is warranted to corroborate our findings.

\section{Conflict of Interest Statement}

Authors have nothing to disclose with regard to commercial support.

\section{References}

1. Raja SG, Navaratnarajah M, Fida N, Kitchlu CS. For patients undergoing coronary artery bypass grafting at higher risk of stroke is the single cross-clamp technique of benefit in reducing the incidence of stroke? Interact Cardiovasc Thorac Surg. 2008;7:500-3.

2. Edelman JJ, Yan TD, Bannon PG, Wilson MK, Valley MP. Coronary artery bypass grafting with and without manipulation of the ascending aorta - a meta-analysis. Heart Lung Circ. 2011;20:318-24.

3. Serruys PW, Morice MC, Kappetein AP, Colombo A, Holmes DR, Mack MJ, et al Percutaneous coronary intervention versus coronary-artery bypass grafting for severe coronary artery disease. N Engl J Med. 2009;360:961-72.

4. Genereux P, Bernard S, Palmerini T, Caixeta A, Rosner G, Reiss GR, et al. Incidence, predictors, and impact of neurological events in non-ST-segment elevation acute coronary syndromes: the ACUITY trial. EuroIntervention. 2014; doi:10.4244/EIJY14M07_06.

5. Emmert MY, Seifert B, Wilhelm M, Grunenfelder J, Falk V, Salzberg SP. Aortic no-touch technique makes the difference in off-pump coronary artery bypass grafting. J Thorac Cardiovasc Surg. 2011;142:1499-506.

6. Vallely MP, Potger K, McMillan D, Hemli JM, Brady PW, Brereton RJ, et al Anaortic techniques reduce neurological morbidity after off-pump coronary artery bypass surgery. Heart Lung Circ. 2008;17:299-304.

7. Edelman JJ, Yan TD, Vallely MP. Anaortic off-pump coronary artery bypass grafting: the criterion standard for minimization of neurologic injury. $J$ Thorac Cardiovasc Surg. 2012;143:251-2.

8. Hattler B, Messenger JC, Shroyer AL, Collins JF, Haugen SJ, Garcia JA, et al. Off-pump coronary artery bypass surgery is associated with worse arterial and saphenous vein graft patency and less effective revascularization: results from the Veterans Affairs randomized on/off bypass (ROOBY) study group. Circulation. 2012;125:2827-35.

Key Words: Coronary artery bypass grafting, postoperative complication, stroke, death 